\title{
Social Living Lab Methodology
}

By Ana Alonso Curbelo \& Mark Wong, University of Glasgow 31.7.20

Social living labs facilitate researchers, professionals/practitioners, data scientists/developers, industry, policy community, and local residents to coconstruct informed learning and practical solutions for social problems that are of local and/or national significance.

Living labs were originally developed in the mid-2000s with a product development focus (Franz, 2015; Schumacher, 2015, p.4). They typically involve a diverse group of participants and bring together researchers and community stakeholders to work collaboratively to generate a user-centred "open innovation ecosystem". At the forefront of the living lab methodology is a co-creation approach, which seeks to integrate research and innovation processes into real life settings with service and product users (Garcia Robleset al., 2016, p.13). This includes engagement with members of the public for purposes including evaluation of innovative ideas, problem-solving through collaboration, development of policy, as well as designing new products and services.

More recently, the living lab approach has been used in socially-oriented research. Social living labs intentionally extend beyond the commercial and product-centred goals of original "living labs", and they seek to co-create citizen-led solutions and innovations to address social issues and challenges (Hughes, Foth and Mallan, 2019).

To build knowledge around connected homes and digital living across the UK, the social living lab methodology provides our research an ideal avenue, as instead of viewing digital technology instrumentally (i.e. as a final product of a lab process), a more holistic view is adopted, which understands 'the digital' as comprising engagement with technology in multi-faceted, dynamic, and localised social processes (Collin, Notley and Third, 2018). Social living lab method and its recent shift to its more 'social' application has influenced the adoption of terminology that is more suitable to social science research (Allan, Dezuanni and Mallan, 2018). For instance, using terms such as 'space of encounter' instead of 'real-life environment', 'open concept' instead of 'experimental environment', and 'public' instead of 'user' (Franz, 2015, p. 59). This shifting terminology reflects the ultimate aims of social living labs to promote enhancement of "community well-being through shared exploration, experimentation, co-creation and evaluation in relation to particular social concerns" (Hughes et al., 2018).

Phases of social living labs include:

\begin{tabular}{|l|l|}
\hline Co-creation & $\begin{array}{l}\text { Pharing views, constraints and knowledge as a basis for } \\
\text { exploring new ideas about products and services; }\end{array}$ \\
\hline Exploration & $\begin{array}{l}\text { Engaging stakeholders in live scenarios that play out the ideas } \\
\text { for new products and services; }\end{array}$ \\
\hline Experimentation & $\begin{array}{l}\text { Testing the products and services in real situations experience } \\
\text { live scenarios with many users and collecting data for } \\
\text { evaluation; }\end{array}$ \\
\hline Evaluation & $\begin{array}{l}\text { assessing new concepts and products using the data collected } \\
\text { during the evaluation phase through various socio-ergonomic, } \\
\text { socio-cognitive and socio-economic lenses; and identifying their } \\
\text { potential for widespread adoption }\end{array}$ \\
\hline
\end{tabular}


Our research adopts a social living lab methodology and integrates living lab's principles with mixed-methods, including qualitative, survey, and secondary data analysis.

From the initial 400 households, the research will work with a subset of households (30 per site) selected based on a range of household-level determinants and factors (e.g. ethnicity mix, disability/care needs, and neighbourhood) to better understand household's abilities and outcomes in achieving wellbeing and sustainability in digital living. This smaller subset will provide a real and conceptual space for deeper engagement with households and 'for mutual knowledge exchange and cooperative learning processes' (Franz, 2015, p. 63). In doing so, the social living lab serves as a catalyst for community engagement, and we will employ 'living methods', which include interactive and engaging methods that stimulate co-construction of knowledge and practical solutions. We will use a range of visual and creative co-design methods exploring and using a wide range of information and media (physical objects, print and digital, photo elicitation, diaries, videos, design ethnography, participatory architecture). Beyond being solely qualitative and survey-based, the research applies methods which are innovative and participatory, with the aim to foster inclusive innovation and design.

Such a mixed-methods approach allows the generation of, and access to, data at different scales and granularity - from individual households (e.g. interviews, diaries, biographies, qualitative/participatory studies), social and digital networks (e.g. network analysis, visualisations), to population and society at large (e.g. secondary data, panel survey, discourse/policy analysis). This will provide much-needed knowledge, evidence and analysis of connected homes with in-depth nuanced insights alongside understandings of overall patterns of digital living at scale. The new research has the potential to be transformative for homes and households, and co-create open spaces for critique, exploration, and innovation to navigate digital living and wellbeing.

\section{Bibliography}

Allan, C., Dezuanni, M., \& Mallan, K. (2018). Digital Storytelling for Community Participation: The Storyelling Social Living Lab. In Digital Participation through Social Living Labs (pp. 245-262). Chandos Publishing.

Collin, P. J., Notley, T., \& Third, A. (2018). Cultivating (Digital) Capacities: A Role for Social Living Labs?. In Digital Participation through Social Living Labs (pp. 19-35). Chandos Publishing.

Franz, Y. (2015) Designing social living labs in urban research. Info 17(4), 53-66. https://doi.org/10.1108/info-01-2015-0008

Garcia Robles, A., Hirvikoski, T., Schuurman, D. \& Stokes, L. (2016). Introducing ENoLL and its living lab community. Brussels: European Network of Living Labs. Available at: https://issuu.com/enoll/docs/enollprint?e=23453591/33195876

Hughes, H., Foth, M., Dezuanni, M., Mallan, K., \& Allan, C. (2018). Fostering digital participation and communication through social living labs: a qualitative case study from regional Australia. Communication research and Practice, 4(2), 183-206.

Hughes, H., Foth, M., \& Mallan, K. (2019). Social living labs for informed learning: A conceptual framework of interprofessional education in community healthcare. Journal of Information Literacy, 13(2), 112-135.

Schumacher, J. (2015). Alcotra Innovation Project: Living labs definition, harmonization cube indicators and good practices. Available at:

http://www.alcotrainnovation.eu/progetto/doc/Short_guide_on_Living_Labs_and_some_good_practices.pdf

Notes

The selected or constructed 'space of encounter' where 'phases of interaction' with citizens can occur provides a real and conceptual space 'for mutual knowledge exchange and cooperative learning processes' (Franz, 2015, p. 63). 